\title{
Physical and Numerical Simulation of Cold Rolling and Heating during Continuous Annealing of DP Steel Strips
}

\section{Lukasz Madej $^{1, a^{*}}$, Norbert Kwiaton ${ }^{2, b}$, Roman Kuziak ${ }^{3, c}$, Mateusz Sitko ${ }^{1, d}$ and Maciej Pietrzyk ${ }^{1, \mathrm{e}}$}

\author{
${ }^{1}$ AGH University of Science and Technology, al. Mickiewicza 30, 30-059 Kraków, Poland \\ ${ }^{2}$ Salzgitter Mannesmann Forschung GmbH, Eisenhüttenstraße 99, 38239 Salzgitter, Germany \\ ${ }^{3}$ Institute for Ferrous Metallurgy, ul. K. Miarki 12, Gliwice, Poland \\ amadej@agh.edu.pl, ${ }^{b} \mathrm{~N} . K w i a t o n @ s z . s z m f . d e,{ }^{c}$ rkuziak@imz.pl, ${ }^{\mathrm{a}}$ msitko@agh.edu.pl, \\ cmaciej.pietrzyk@agh.edu.pl,
}

Keywords: Cold rolling, dual phase, numerical simulation.

\begin{abstract}
Development of fast and efficient finite element model for rolling industrial grades of two DP steels is the subject of the present paper. Basis of the finite element framework, as well as material model development stages, are presented first. Model validation with experimental measurements is shown next. Finally, selected examples of multi scale modelling including microstructure scale are presented to complement presented investigation and show possibilities of future developments.
\end{abstract}

\section{Introduction}

The DP steel is a composite of ductile ferrite and hard martensite and can also contain some bainite and retained austenite [1,2]. Typical industrial manufacturing chain for a car part made of these steels is shown in Figure 1. Problem of modeling of that chain was discussed in earlier publication [3]. Important parameters, which are transferred between subsequent devices in the simulation are shown in Figure 1. These include: $D_{\gamma}$ - austenite grain size, $\sigma_{p}$ - flow stress, $F_{f}, F_{m}-$ volume fractions of ferrite and martensite, respectively, $\varepsilon$ - strain.

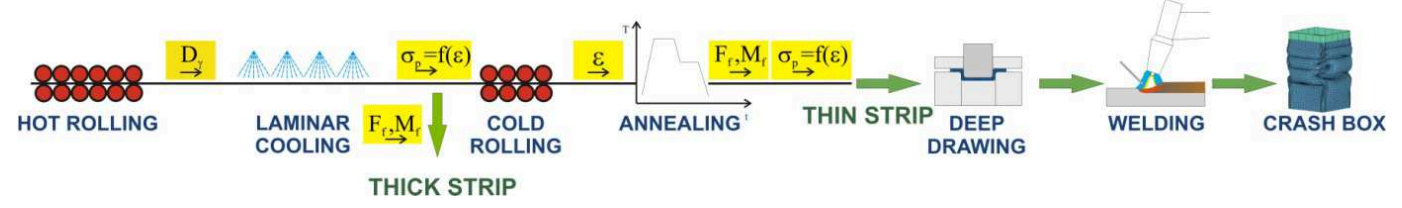

Figure 1. Typical manufacturing chain for automotive part made of DP steel strip.

For thin strips the DP microstructure is mainly affected during continuous annealing [2,4]. In this context, having in mind that keeping the loads in cold rolling as low as possible is crucial, a typical soft ferritic-pearlitic microstructure is obtained after laminar cooling following the hot rolling. It can make an impression that modeling of cold rolling is of less importance. On the other hand, microstructure after cold rolling is an input for simulations of recrystallization of deformed ferrite and austenitizing during the continuous heating. In this context simulations of cold rolling appears as an important step in the manufacturing cycle. Therefore, physical and numerical simulation of cold rolling and heating before continuous annealing is the main objective of the present work.

\section{Laboratory Cold Rolling Mill}

Experiments were performed on the laboratory cold rolling mill in Salzgitter (Figure 2). The rolling mill is equipped with hydraulic cylinders to enable rolling with strip tension. 


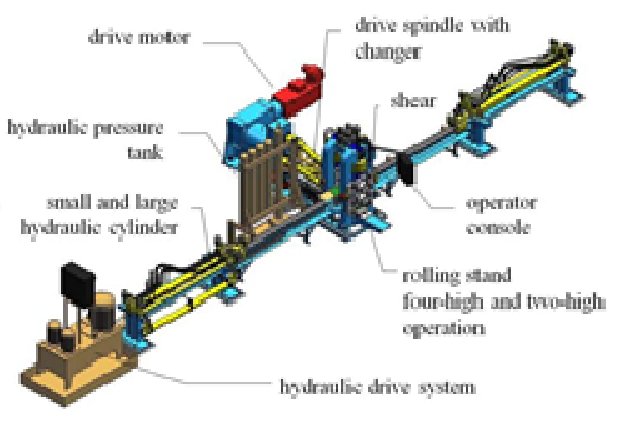

Figure 2. View of the laboratory cold rolling mill from Salzgitter Mannesmann Forschung GmbH

The parameters of the rolling mill used in the experiment were: work roll diameter $D_{w}=147.9 \mathrm{~mm}$ and back up roll diameter $D_{b}=360.18 \mathrm{~mm}$, rolling velocity $v=0.1 \mathrm{~m} / \mathrm{s}$. Dimensions of the stock material were: initial thickness $h_{0}=4.0 \mathrm{~mm}$, width $b=135 \mathrm{~mm}$ and length $l=471 \mathrm{~mm}$. The following rolling schedule was investigated: $4.0 \Rightarrow 2.88 \Rightarrow 2.2 \Rightarrow 1.81 \Rightarrow 1.6 \mathrm{~mm}$. Back and front tensions were applied to decrease the load and to improve the shape of the strip.

\section{Model}

Finite Element Framework. The Finite Element (FE) solution that was adopted for the present project was used in the two aspects of research: as a direct problem model in the inverse analysis and as a model of the rolling process of the laboratory cold rolling mill in Salzgitter.

The FE solution is based on the rigid-plastic thermo-mechanical finite element concept proposed in [5]. Detailed description of the algorithm and the program, which were used in this work, is given in [6]. The solution assumes that material obeys Huber-Mises yield criterion and associated LevyMises flow rule. The velocity field is calculated by searching for a minimum of the power functional:

$$
J=\int_{\Omega}\left(\sigma_{i} \dot{\varepsilon}_{i}+\lambda \dot{\varepsilon}_{V}\right) d \Omega-\int_{\Gamma} \mathbf{f}^{T} \mathbf{v}_{s} d \Gamma
$$

where: $\sigma_{i}$ - effective stress, which is equal to the flow stress $\sigma_{p}, \dot{\varepsilon}_{i}$ - effective strain rate, $V$ volume, $S$ - contact surface, $\dot{\varepsilon}_{V}$ - volumetric strain rate, $\lambda$ - Lagrange multiplier, $\mathbf{f}$ - vector of boundary tractions, $\mathbf{v}_{S}$ - vector of velocities.

In the flow theory of plasticity, strain rates are related to stresses by the Levy-Mises flow rule [5]. Friction plays an important role in the inverse analysis of plastometric tests and in modeling of rolling. The friction model suggested by Chen and Kobayashi [5], was used in the present work.

During experiments it was observed that deformation heating causes significant increase of the sample temperature in the plastometric tests and in the rolling process. Proper prediction of the temperature increase is an inevitable condition for obtaining realistic results. Therefore, the flow formulation, which is the basis of the mechanical model in the present work, was coupled with the finite element solution of the Fourier heat transfer equation:

$$
\nabla \cdot k \nabla T+Q=c \rho \frac{\partial T}{\partial t}
$$

where: $k$ - conductivity, $Q$ - rate of the heat generation rate due to deformation work, $c$ - specific heat, $\rho$-density, $T$ - temperature, $t$ - time.

Discretization of the problem was performed in a typical finite element manner and simulations of plastometric compression tests and cold rolling process were performed. 
Material Model. The investigated material was DP steel, hot rolled with the end of rolling temperature of $910{ }^{\circ} \mathrm{C}$. The chemical composition of the steel is given in Table 1. Two sets of experiments were performed for the coiling temperatures of $620^{\circ} \mathrm{C}$ (Trial A) and $710{ }^{\circ} \mathrm{C}$ (Trial B).

Table 1. Chemical composition of the investigated steel, wt $\%$.

\begin{tabular}{|c|c|c|c|c|c|c|c|c|}
\hline $\mathrm{C}$ & $\mathrm{Si}$ & $\mathrm{Mn}$ & $\mathrm{P}$ & $\mathrm{N}$ & $\mathrm{Al}$ & $\mathrm{Cr}+\mathrm{Mo}$ & $\mathrm{V}+\mathrm{Ti}+\mathrm{Nb}$ & $\mathrm{B}$ \\
\hline 0.10 & 0.3 & 2.1 & 0.011 & 0.004 & 0.04 & 0.42 & 0.085 & 0.0035 \\
\hline
\end{tabular}

Uniaxial compression tests were then performed to determine flow stress of the steel. Samples measuring $\varnothing 3.22 \times 9 \mathrm{~mm}$ were compressed at the Gleeble 3800 simulator in temperatures 20,100 and $150{ }^{\circ} \mathrm{C}$ with strain rates $0.1,1$ and $10 \mathrm{~s}^{-1}$ up to the total strain of 0.5 . To determine the reliable flow stress data of the investigated material, independent of the inhomogeneities occurring in the tests, an inverse analysis was applied [7]. Load vs. displacement data were monitored and surface temperature of the sample was measured during each test. Selected examples of the registered loads for the trial A are shown in Figure 3, while temperatures measured in these tests are shown in Figure 4. It is seen that temperature increases during the test. In slow tests there is enough time for heat to be transferred to the tool and for the control system to correct the temperature. In consequence reasonably stable temperature was obtained for the strain rate of $0.1 \mathrm{~s}^{-1}$. The temperature increase is more pronounced in faster tests, therefore, inverse analysis was applied to account for this increase.

Selected examples of the registered loads for the material from the trial B are shown in Figure 5. Comparison of measured loads for two materials is shown in Figure 6. It is seen that difference in loads between these materials is negligible. Therefore, all other investigations were performed only for the trial A. Based on these experimental data an inverse analysis was used to determine the flow stress corrected against the effect of friction and deformation heating in plastometric tests. Results of this analysis for the investigated DP steel from the trial A are shown in Figure 7.
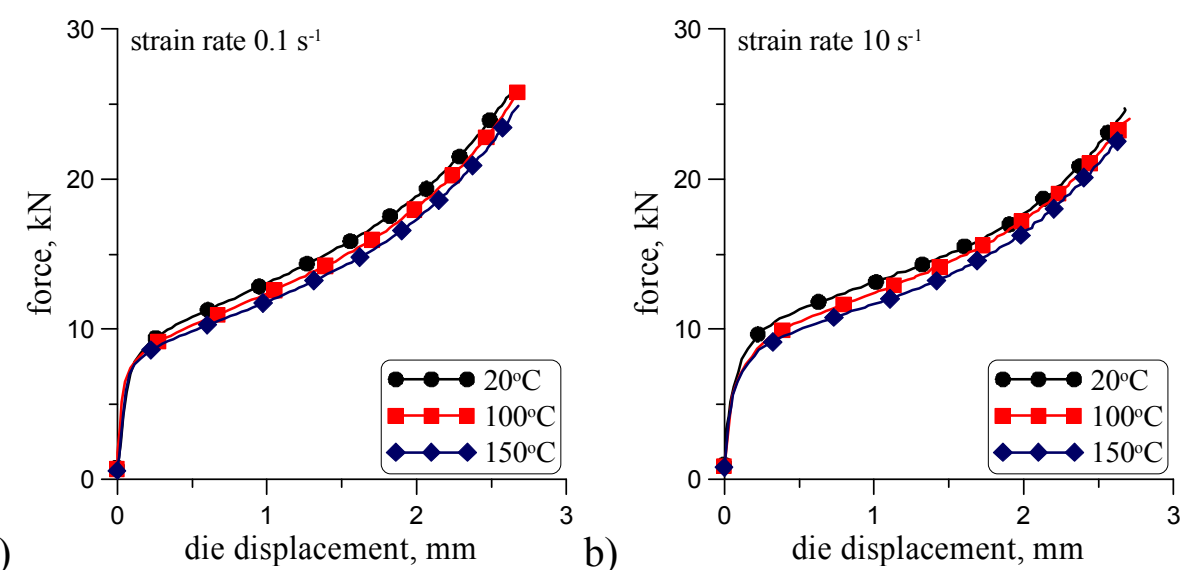

b)

Figure 3. Selected examples of loads recorded in the tests for the material from the trial A.

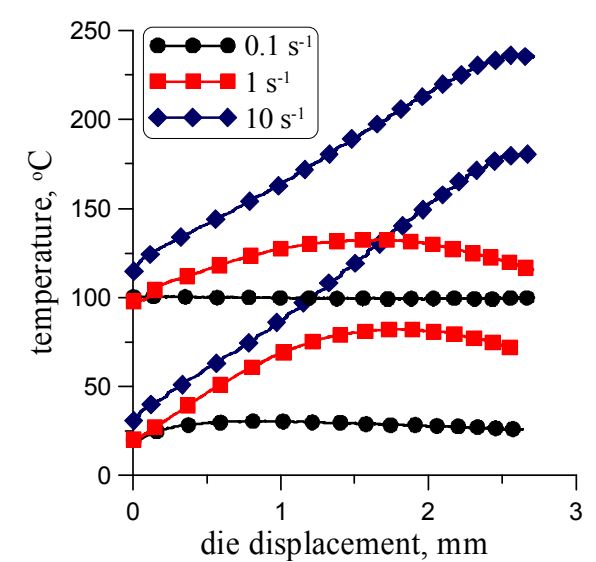

Figure 4. Selected examples of temperature measurements in tests for the material from the trial A. 


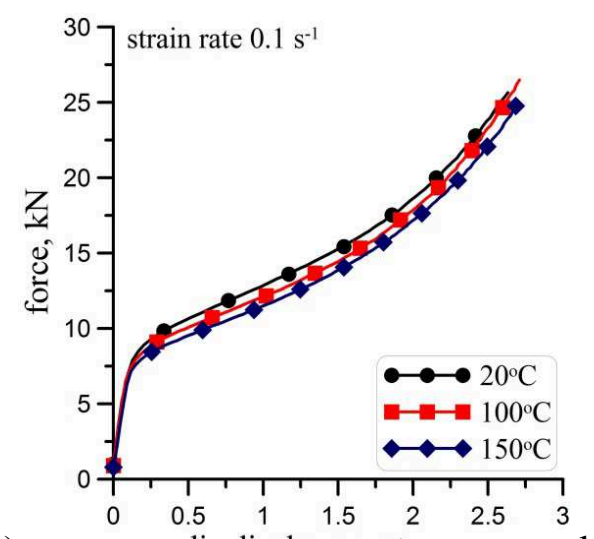

a)

die displacement, $\mathrm{mm}$

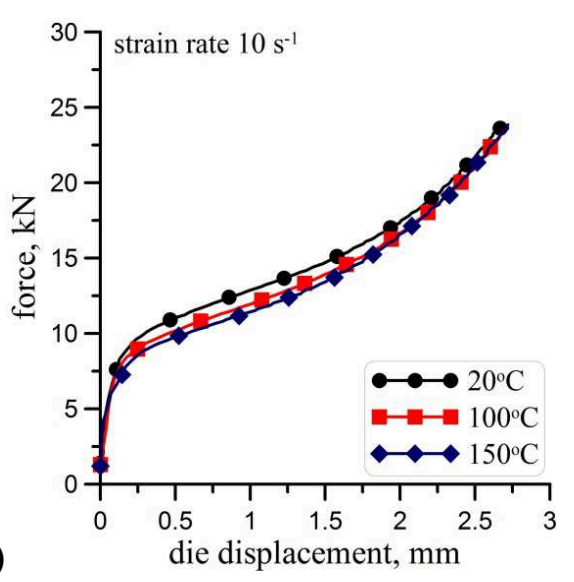

b)

Figure 5. Selected examples of loads recorded in the tests for the material from the trial B.

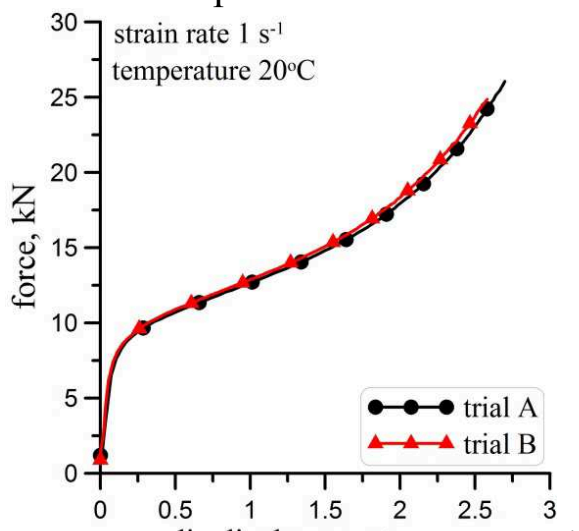

a)

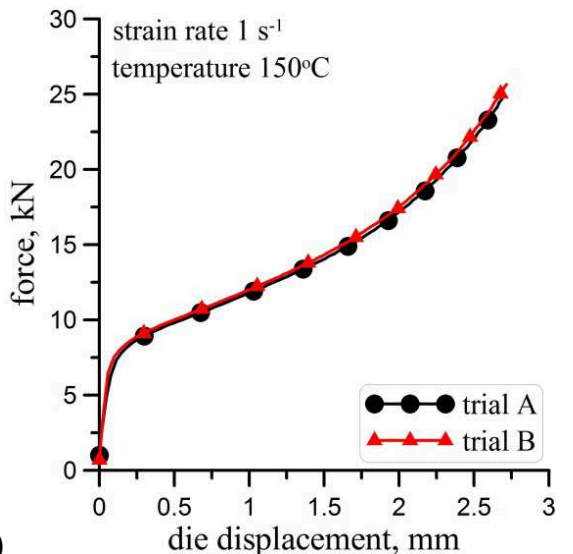

Figure 6. Comparison of loads measured for the materials from the trials A and B.

As mentioned, curves represent flow stress as a function of strain and were obtained in a tabular form from the inverse analysis. This relation can be considered a property of the material for isothermal, constant strain rate conditions. However, the flow stress in FE simulations has to be described in a wide range of temperatures and strain rates. Thus, the next step of the inverse analysis included determination of the coefficients of the function describing the flow stress. These coefficients were considered as variables in the optimization.
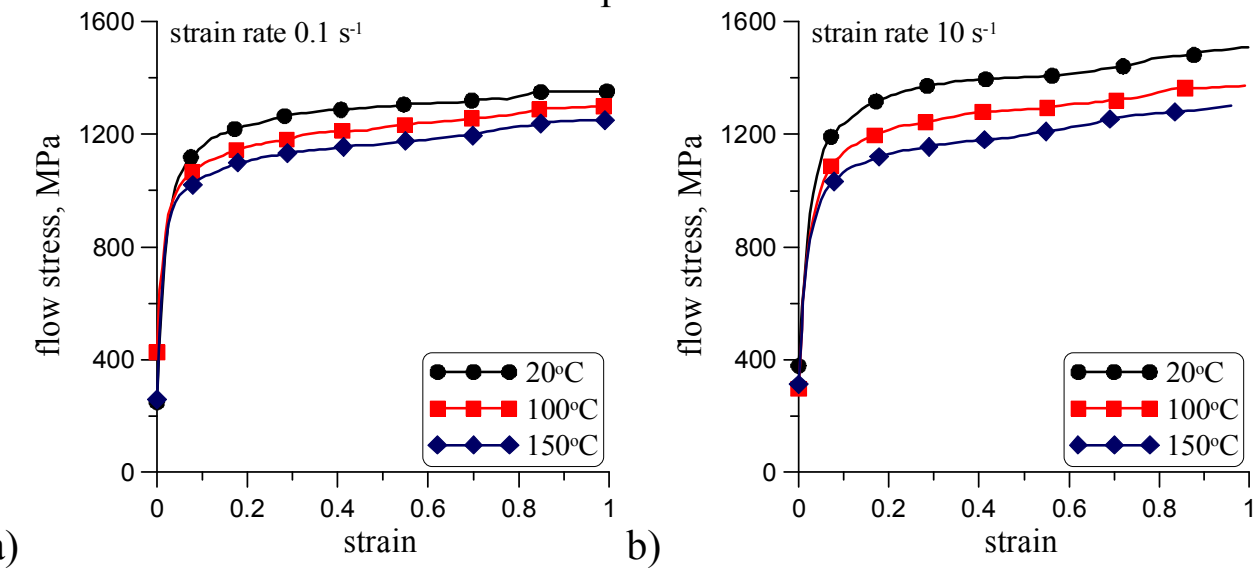

Figure 7. Flow stress of the investigated DP steel from the trial A determined using inverse analysis, for the strain rates of $0.1 \mathrm{~s}^{-1}(\mathrm{a}), 10 \mathrm{~s}^{-1}(\mathrm{~b})$.

The simplest form of the Hansel-Spittel [8] equation was considered in the present work:

$$
\sigma_{p}=A \varepsilon^{B} \dot{\varepsilon}^{C} \exp (-D T) \exp (-E \varepsilon)
$$

The coefficients determined using the inverse analysis are $A=1483.2, B=0.0948, C=0.010184$, $D=0.8858$ and $E=0.000012$. Since a very low value of the coefficient $E$ responsible for softening was obtained, this term was omitted in further investigation. 


\section{Simulations of the Experimental Rolling}

Simulation of the investigated rolling process was performed with the developed material model. Coulomb friction coefficient of 0.07 and heat exchange coefficient of $25 \mathrm{~kW} / \mathrm{m}^{2} \mathrm{~K}$ [9] were assumed in the simulations. Front and back tension recorded during rolling is shown in Figure 8a and these values were used in boundary conditions for equation (1). Comparison of the measured and calculated rolling forces is shown in Figure $8 \mathrm{~b}$. Beyond some overestimation of the force in passes 2 and 3, reasonably good agreement between measurements and predictions is observed.

All rolling parameters for all passes were calculated by the FE code and selected results are presented below. Due to symmetry only upper half of the roll gap is presented in Figure 9, which shows distribution of strain, strain rate, average stress and temperature in the roll gap in the $1^{\text {st }}$ pass.
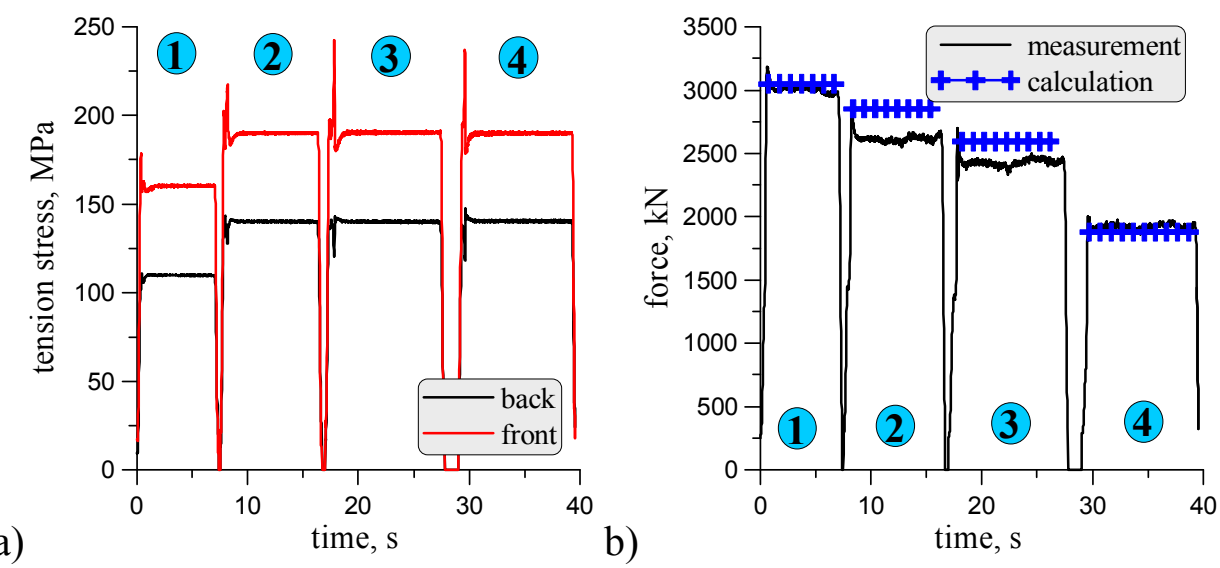

Figure 8. Tensions recorded during experimental rolling (a) and comparison of measured and calculated forces (b) in this process.
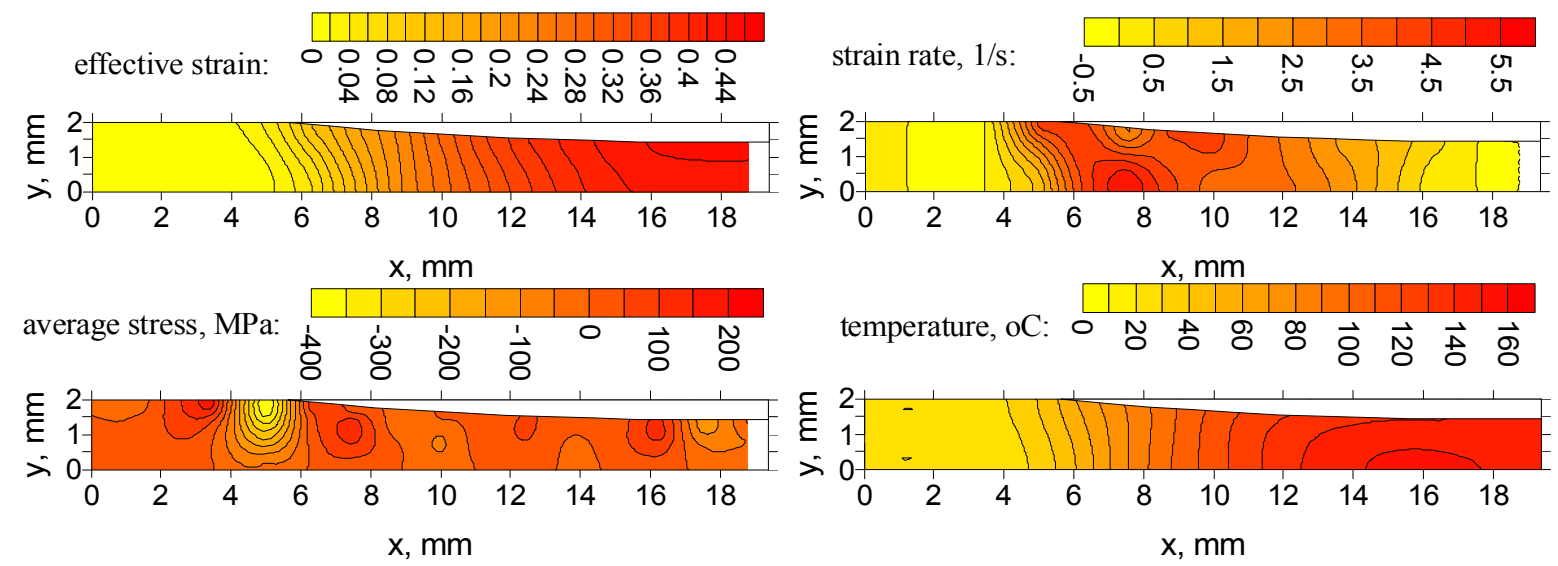

Figure 9. Distributions of effective strain, strain rate, average stress and temperature in the roll gap in the first pass.

It is seen that due to deformation heating the temperature increases approx. $100{ }^{\circ} \mathrm{C}$. Calculated distribution of strains after the $4^{\text {th }}$ pass was then used in simulations of the recrystallization of ferrite during the first stage of continuous annealing. A micro scale analysis was realized to investigate strain inhomogeneities occurring along the microstructure during and after cold rolling, as well as during heating when static recrystallization (SRX) of ferrite occurs. Ferritic-pearlitic microstructure after SRX obtained using the developed CA model [10] is shown in Figure 10.

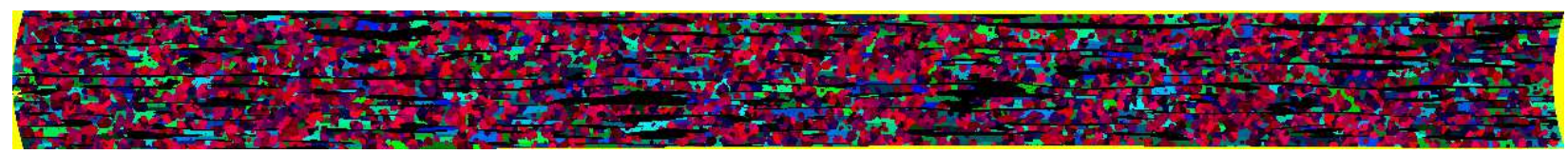

Figure 10. Microstructure after recrystallization with physical dimension $690 \times 60 \mu \mathrm{m}$. 
As seen in Figure 10 approximately $75 \%$ of microstructure is recrystallized and final grain size is slightly below $2 \mu \mathrm{m}$. The nucleation and grain growth in that case was strictly related to the inhomogeneous strain distribution obtained from the finite element simulation of cold rolling on the basis of the developed material model.

\section{Summary}

The finite element model with the developed material model provided an accurate prediction of macro scale material response in the case of loads. Thus, it can be used to design rolling schedules at the industrial scale. Differences between two investigated trials A and B were negligible, what suggests that coiling temperature in these cases did not have significant effect on microstructure behavior. Developed material model can also be used in the multi scale solution providing additional information on influence of inhomogeneous deformation on static recrystallization kinetics, what is important from further modeling point of view of complete continuous annealing cycle. Analysis of results of micro scale simulations pointed out strong inhomogeneities of strains after rolling. The local strains were reaching value of 2 for the nominal total strain of 0.6 . This has direct influence on nucleation of SRX occurring primarily in the areas between pearlite islands.

\section{References}

[1] P. Suwanpinij, N. Togobytska, Prahl U., Weiss W., Hoemberg D., Bleck W., Numerical cooling strategy design for hot rolled dual phase steel, Steel Res. Int., 81 (2010) 22-28.

[2] R. Kuziak, R. Kawalla, S. Waengler, Advanced high strength steels for automotive industry, Arch. Civil Mech. Eng., 8 (2008) 103-117.

[3] R. Kuziak, M. Pietrzyk, Physical and numerical simulation of the manufacturing chain for the DP steel strips, steel research international, special edition conf. ICTP, Aachen, (2011) 756-761.

[4] C. Bos, M.G. Mecozzi, J. Sietsma, A microstructure model for recrystallisation and phase transformation during the dual-phase steel annealing cycle, Comp. Mater. Sci., 48 (2010) 692-699.

[5] S. Kobayashi, S.I. Oh, T. Altan, Metal forming and the finite element method, Oxford University Press, New York, Oxford, 1989.

[6] M. Pietrzyk, Finite element simulation of large plastic deformation, J. Mat. Proc. Tech., 106 (2000) 223-229.

[7] D. Szeliga, J. Gawąd, M. Pietrzyk, Inverse analysis for identification of rheological and friction models in metal forming, Comp. Meth. App. Mech. Eng., 195 (2006) 6778-6798.

[8] A. Hensel, T. Spittel, Kraft- und Arbeitsbedarf bildsamer Formgebungsverfahren, VEB Deutscher Verlag für Grundstoffindustrie, Leipzig, 1979.

[9] M. Pietrzyk, H. Kusiak, J.G. Lenard, Z. Malinowski, Heat exchange between the workpiece and the tool in metal forming processes, Proc. FORMABILITY'94, ed., J. Bartecek, (1994) 329-338.

[10]L. Madej, L. Sieradzki, M. Sitko, K. Perzynski, K. Radwański, R. Kuziak, Multi scale cellular automata and finite element based model for cold deformation and annealing of a ferritic-pearlitic microstructure, Comp. Mater. Sci., 77, 2013, 172-181. 